\title{
The Harm of Microorganisms in Low Temperature Meat Products and Its Control Technology
}

\author{
Lei Li \\ School of Chemistry and Engineering, Wenshan University, Wenshan, Yunnan, 663099, China
}

Keywords: Low temperature meat products; Microorganism; Harm; Control

\begin{abstract}
Control of microorganism in low-temperature meat products is a common problem in the basic scientific research, production, application and industrialization. Low-temperature meat products are rich in nutrition and high in moisture content, which provides a sound growth condition for microorganism. It is easy to be dyed and spoiled, which will not only reduce the profits of enterprises, but also will have a negative impact on the external image of the enterprise. Based on the author's study and practical experience, this paper first analyzed the common microorganisms in low temperature meat products, and then put forward the effective control measures for low temperature meat products.
\end{abstract}

\section{Introduction}

China is the largest producer and consumer of meat in the world. As a representative of neutral food, low temperature meat products are rich in variety and maintain the original nutrition and inherent flavor to the maximum extent. Thus, it is very popular among masses of consumers. Low temperature meat products are rich in protein and fat and high in water activity, which is conducive to the growth and reproduction of spoilage microorganism, ranging from raw meat, accessories, spices and other additives to finished products. The source pollution and secondary pollution are difficult to control thoroughly, and the temperature of heat processing is low and the sterilization is not thorough, so some heat-resistant microbes still exist. All these causes lead to microorganism corruption in low temperature meat products, which are also the main reasons for the short shelf life of low temperature meat products. It is not convenient for long-distance transportation and unbalanced circulation and consumption.

\section{Common Microorganisms in Low Temperature Meat Products}

\subsection{Species of microorganisms in low temperature meat products}

There are many microorganisms in low temperature meat products, mainly including mold, Escherichia coli, Staphylococcus aureus, Clostridium botulinum, Listeria, Salmonella and Aerobacterium. According to the temperature type, it can be divided into low temperature type, medium temperature type and high temperature type microorganisms. Further, as for the specific thermophilic microorganism, the minimum growth temperature is $-12{ }^{\circ} \mathrm{C}$, and the optimum growth temperature is $5{ }^{\circ} \mathrm{C}$, and the maximum growth temperature is $1520{ }^{\circ} \mathrm{C}$. As for the facultative thermophilic microorganism, the lowest growth temperature is $-5^{\circ} \mathrm{C}$, and the optimal temperature is 10 to $20^{\circ} \mathrm{C}$, and the highest growth temperature is 25 to $30^{\circ} \mathrm{C}$. As for the mesophiles, the minimum growth temperature is 10 to $20{ }^{\circ} \mathrm{C}$, and the optimum growth temperature is 20 to $40{ }^{\circ} \mathrm{C}$, and the maximum growth temperature is 40 to $45{ }^{\circ} \mathrm{C}$. As for the high temperature microorganism, the minimum growth temperature is 25 to $45{ }^{\circ} \mathrm{C}$, and the optimum growth temperature is 50 to $60{ }^{\circ} \mathrm{C}$, and the maximum growth temperature is 70 to $95^{\circ} \mathrm{C}$.

\subsection{Characteristics of microorganisms in low temperature meat products}

Microorganisms in low-temperature meat products, like other organisms, have the characteristics of small shape, simple structure, wide distribution, fast growth and reproduction, and need to 
continuously absorb all kinds of nutrients, such as carbon sources, nitrogen sources, energy sources, growth factors, inorganic salts, water from the external environment, so that to synthesize their own cellular substances and provide the energy that body needs for all kinds of physiological activities. Only in this way can the organism grow and reproduce normally and guarantee the continuity of its life. Under suitable conditions, microorganism can reproduce for 20 to 30 minutes.

\subsection{Dependence of microorganisms on low temperature meat products}

Low temperature meat products are rich in nutrients and are chemically composed of proteins, fats, carbohydrates, moisture and other trace components (such as cellulose, pigments and flavor compounds). It provides a good growth environment for microorganisms and is very suitable for the growth and reproduction of microbes.

\section{Effective Control Strategy of Middle Temperature Meat Products}

\subsection{Quality control of raw and additive materials}

(1) Selection and quality control of raw meat. In the processing of low temperature meat products, the first step is to select the raw materials. The number of bacteria in raw meat is less than $1 \times 105$ in per gram, and the volatile base nitrogen should be less than $20 \mathrm{mg}$ in every $100 \mathrm{~g}$. The growth rate of microorganism reproduction period is lower, which is beneficial to the control of microorganism in the subsequent production and processing process. The study shows that the quality control measures of raw meat include the following: Feed additive should be used reasonably in the stage of animal feeding and a new type of feed additive namely green feed additive; it should be used as far as possible. We should ensure that raw meat is free of toxic side effects, veterinary drugs and heavy metals and other harmful substances residue; we have to do pre-mortem quarantine in accordance with the prescribed procedures. We must keep the production workshop, equipment and tools clean. Before the production, we can use hot water to scour the equipment, and the production can be carried out after the end of the production. After the production is finished, we must wash and disinfect the equipment, tools and floors. The temperature of the defrosting area should be controlled below 15 degrees. We should use proper thawing method to thaw thoroughly, and the center temperature of raw meat thawed should be controlled below $4{ }^{\circ} \mathrm{C}$; if necessary, borneol should be adjusted to shorten the thawing processing time of raw meat. We should avoid increasing local temperature during thawing process to facilitate microorganism reproduction. After the slaughter of animals, the quarantine inspection of raw meat should be in accordance with the provisions of the standard of GB2707 fresh "Fresh (frozen) animal meat hygienic standard"and then it can be used. When in preparation, we should avoid to use the lymphoid, blood and other inferior meat.

(2) Quality control of additive materials. In the process of processing low temperature meat products, the main additives are various kinds of phosphate, protein, starch, gum, salt, sugar, spices, pigments, etc. These substances contain a certain number of bacteria, if the manufacturer's sanitary conditions are poor, then the amount of bacteria in the additives is incalculable. The quality control measures of the additives include the following contents: the additives are accepted strictly in accordance with the GB2760 Food Additive Use Hygienic Standard, and all kinds of additives must be issued by the manufacturers with a laboratory certificate. We should carry on necessary sterilization treatment when the additive is used; The purchase of accessories should follow the principle of small batch and multiple batches to ensure freshness; the storage room of additives should have better temperature control, ventilation, dustproof, moisture-proof and other facilities to ensure that the storeroom is clean, ventilated, cool, dry and free of insect and rodent moths, so that to provide special storage conditions for some additives.

\subsection{Control of production and processing processes}

(1) Time control of production process. Low temperature meat products production cycle is long, and process is complex; the process is more than ten working procedures, which generally includes 
thawing, dressing, fine cutting, ingredients, preparation, pickling, rolling, ground meat, chopping, filling, fumigation, sterilization and cooling and packaging. While paying attention to the smooth convergence of production links, low temperature meat products should be as short as possible processing time. Reasonable arrangement of production workshop, shortening the residence time of each processing link, transferring connecting time, cooling and drying time, can achieve that the production process of the whole product be controlled within 8 hours. Thus, we can avoid the proliferation of residual microorganisms in time.

(2) Low temperature control of production process. The temperature of raw material thawing and dressing workshop should be controlled at $10{ }^{\circ} \mathrm{C}$, and the temperature of pickling shop should be controlled at 0 to $4{ }^{\circ} \mathrm{C}$, and the temperature of meat and salt water should be controlled at about $4{ }^{\circ} \mathrm{C}$ in injection process. The temperature of the material at the end of rolling should be controlled at 6 to $10{ }^{\circ} \mathrm{C}$. In the process of emulsification, the high speed emulsification temperature of meat should be controlled at 0 to $4{ }^{\circ} \mathrm{C}$, and the temperature at the end of meat emulsification should be controlled within $12{ }^{\circ} \mathrm{C}$, and the temperature of irrigation workshop should be controlled within $15{ }^{\circ} \mathrm{C}$. The temperature of the finished product shall be controlled at 0 to $4{ }^{\circ} \mathrm{C}$, and the temperature of the storage room of the equipment, such as the hopper, shall not be higher than $14{ }^{\circ} \mathrm{C}$. This can not only control the growth of microorganism in space to a large extent, but also prevent the temperature of semi-finished materials from rising in the process. Thus, it can reduce environmental pollution of semi-finished products and the reproduction of microorganisms in semi-finished materials.

\subsection{Sanitary control and management of production and processing process}

(1) Health control of production personnel. person who obtains the health certificate may participate in this work; hygiene of staff should obey "four diligent", that is, frequent bath, frequent haircut, frequent haircut and frequent change of work clothes; in order to avoid cross-contamination, fresh area, cooked products area personnel must not flow across the area; production personnel should strictly abide by the disinfection system and have a high awareness of hygiene and disinfection, so as to cultivate a good habit of disinfection.

(2) Sanitary control of production equipment and appliances. In all links of production and processing, all instruments and equipment that are in direct or indirect contact with raw materials, accessories and semi-finished materials should be thoroughly cleaned and disinfected before and after the shift, and the tools and containers of production shall be sterilized by hot water and heat. One such small utensils such as repair knife and knife rod should be experienced four procedures disinfection including removed residue, hot water washing, thermal disinfection (boiling in hot water for 30 minutes) and clean water washing. For appliances that are not suitable for thermal disinfection (such as cutting table cases, carts, equipment and accessories, etc.), the meat fillings, grease and other dirt adhered to their surfaces are first cleaned and then sprayed. Wipe or soak them in a certain concentration of disinfectant and sterilize, and then rinse the above disinfectant with clear water. At present, more chemical disinfectants are used in China (bleach powder) and peracetic acid, etc.

(3) Hygiene control of the production environment. We should keep clean in production operation between the walls, doors and windows of low temperature meat, and the ceiling must be kept clean without dead angle of hygiene and waste water retention. We should use ozone or ultraviolet lamp to sterilize the operation room 3 times everyday, and each time sterilization time is not less than 30 mins. The disinfectant pool should be changed water frequently, and the sewer should keep clean and unobstructed, and the ground is sprayed with $2 \times 10^{-4}$ sodium hypochlorite or chlorine dioxide solution every 2 hours. Production workshop must have anti-fly, anti-rat and dust prevention facilities. Ground hygiene is regularly cleaned and disinfected with fire alkali or dilute hydrochloric acid; the surrounding environment of the workshop should keep clean with no garbage, no dirt, no stagnant water and no pollution sources nearby.

(4) Sanitary control of water for production. Low temperature meat products processing enterprises generally use tap water, and the national water quality standards allow bacteria to be 100 
in per ml. If the production enterprises are using their own water source to process products, it is necessary to sterilize the water quality of water source, such as adding bleach powder or sodium hypochlorite solution to the cistern to ensure the quality of production water.

(5) Full implementation of the HACCP and SSOP management syste. HACCP management system has been recognized as the best management scheme to ensure food safety in the food industry at present. The hygienic standard operating procedure (SSOP) can guide how to carry out cleaning, sterilizing and maintain hygiene during food production and processing. In order to improve the quality of products, SSOP and HAC can be effectively controlled by microorganism contamination and propagation in the process of processing, and combined with GMP management system. We should extend the shelf life of products to provide reliable guarantee.

\section{Conclusions}

In the early production and production process of low temperature meat products, we should reduce raw meat, additives, tools, production environment, personnel, water before sterilization of the original bacteria; in addition, we should strengthen hygiene and disinfection. A good temperature control and moisture control play an important role in reducing microorganism in meat products. At the same time, because of the long production cycle of low temperature meat products, the technological process generally includes more than a dozen processes, which provides a certain time for the growth and reproduction of microorganisms. Workers must be skilled in operation as far as possible to shorten the processing time and improve work efficiency.

\section{References}

[1] Sun Xinsheng, Yang Linghan. Application of Ultra-high Pressure in Low Temperature Meat Products [J]. Anhui Agricultural Science, 2015, (09): 280-282.

[2] Yang Qingwen. Measures for Anticorrosion of Low Temperature Meat products [J]. Aquaculture Technical Adviser, 2013, (01): 216.

[3] Liu Chaoqun, Wang Hongxun, Hou Wenfu. Progress in the Application of Microbial Control and Prediction Models for Low Temperature Meat Products [J]. Food Science, 2009, (21):481-484.

[4] Zhu Meiyun, Li Yu, Pang Lingyun, Lu Juntao. Control of Microorganisms in Low Temperature Meat Products [J]. Processing of Agricultural Products Proceedings (Academic Journal), 2008, (11): 83-85+88

[5] Cai Jian, Jin Xiaohua, Song Hua. Preservation Technology of Meat and Its Products [J]. Processing of Agricultural Products, 2007, (02): 18-20.

[6] Yang Zongqu, Liu Wei, Chen Haijun, Zhu Jun, Dingjun, Shang Binglan, Liu Kebo, Luo Jiquan. A Study on Irradiation Preservation of Low Temperature Meat Products [J]. Food Science, 2001, (09): 84-86. 